\title{
DECISION SUPPORT SYSTEM FOR OPTIMAL DROUGHT MANAGEMENT OF FUKUOKA CITY WATER RESOURCES: APPLICATION TO THE 1994/95 DROUGHT CONDITIONS
}

\author{
Tarek MERABTENE ${ }^{1}$, Kenji JINNO ${ }^{2}$ and Akira KAWAMURA ${ }^{3}$ \\ ${ }^{1}$ Member of JSCE, Master Of Eng., Institute of Environmental Systems, Kyushu University (6-10-1 Hakozaki, Higashi-ku, Fukuoka \\ 812-8581, Japan) \\ ${ }^{2}$ Member of JSCE, Dr. of Eng., Professor, Institute of Environmental Systems, Kyushu University (6-10-1 Hakozaki, Higashi-ku, \\ Fukuoka 812-8581, Japan) \\ ${ }^{3}$ Member of JSCE, Dr. of Eng., Associate Professor, Institute of Environmental Systems, Kyushu University (6-10-1 Hakozaki, \\ Higashi-ku, Fukuoka 812-8581, Japan)
}

The 1994/95 drought posed many challenges for water resources management in Fukuoka City, western Japan, and surrounding communities. During the drought, much effort was expended to maximize available resources and to reduce demand. In this paper, a decision support system is developed for drought operation of the Fukuoka City water supply system. The methodology applied incorporates a genetic algorithm procedure to derive some optimal daily release policies in order to minimize long-term drought damages and water shortage threats. The application of the DSS to the operation of the water supply system of Fukuoka City, reached very promising results.

Key words: Decision support system, reservoir operation, genetic algorithm

\section{INTRODUCTION}

The management of water supply systems during drought is a big challenge for many communities, especially in highly developed areas whose functions are totally dependent on a stable water supply. However, failures of the water supply sources to satisfy the requirements are unavoidable in case of severe droughts. To enhance the robustness and safety of the water supply system and decrease the drought damages, risk management is of primary consideration. This paper presents the development of a decision support system (DSS) for the optimal management of the Fukuoka City water resources during periods of drought. The objective is to develop a comprehensive DSS to improve the quality of decision making when simulating daily operational water supply strategy and water take form the existing sources.

The methodology applied to evaluate the best water take policy, i.e., the one that minimizes the long term drought damages and the risk of system failure, is based on the genetic algorithm (GA) proposed by Holland ${ }^{1)}$. The risk analysis employed in this study utilizes the concept of reliability, resiliency, vulnerability and the drought risk index ${ }^{2,3)}$. In addition to the risk-based reservoir operation model, the DSS combines a database manager, a rainfall-runoff model, and a water demand prediction model.

\section{STUDY AREA}

As shown in Fig. 1, in addition to the water take from the Chikugo barrage, the water supply system of Fukuoka City consists of seven dams, six water intakes for the small surrounding rivers, and six purification plants with a total supply capacity of $704,800 \mathrm{~m}^{3} /$ day. Noteworthy is the Chikugo River from which Fukuoka City receives a third of its average daily water supply of $410,000 \mathrm{~m}^{3} /$ day. During severe droughts, a significant reduction in yield from the Chikugo river is expected because of water sharing conflicts among users, streamflow depletion, and water quality deterioration ${ }^{4}$.

Moreover, despite the large capacity of the dam reservoirs, they are very vulnerable to drought due to their slow recovery (small catchment area and steep surface slopes). For successful operation, the reservoir storage levels must recover to near the full capacity after the rainy season. The average precipitation during the rainy season (Jun to July) is about $950 \mathrm{~mm}$. Thus, the system also depends on the typhoon season (September to October) to partially 


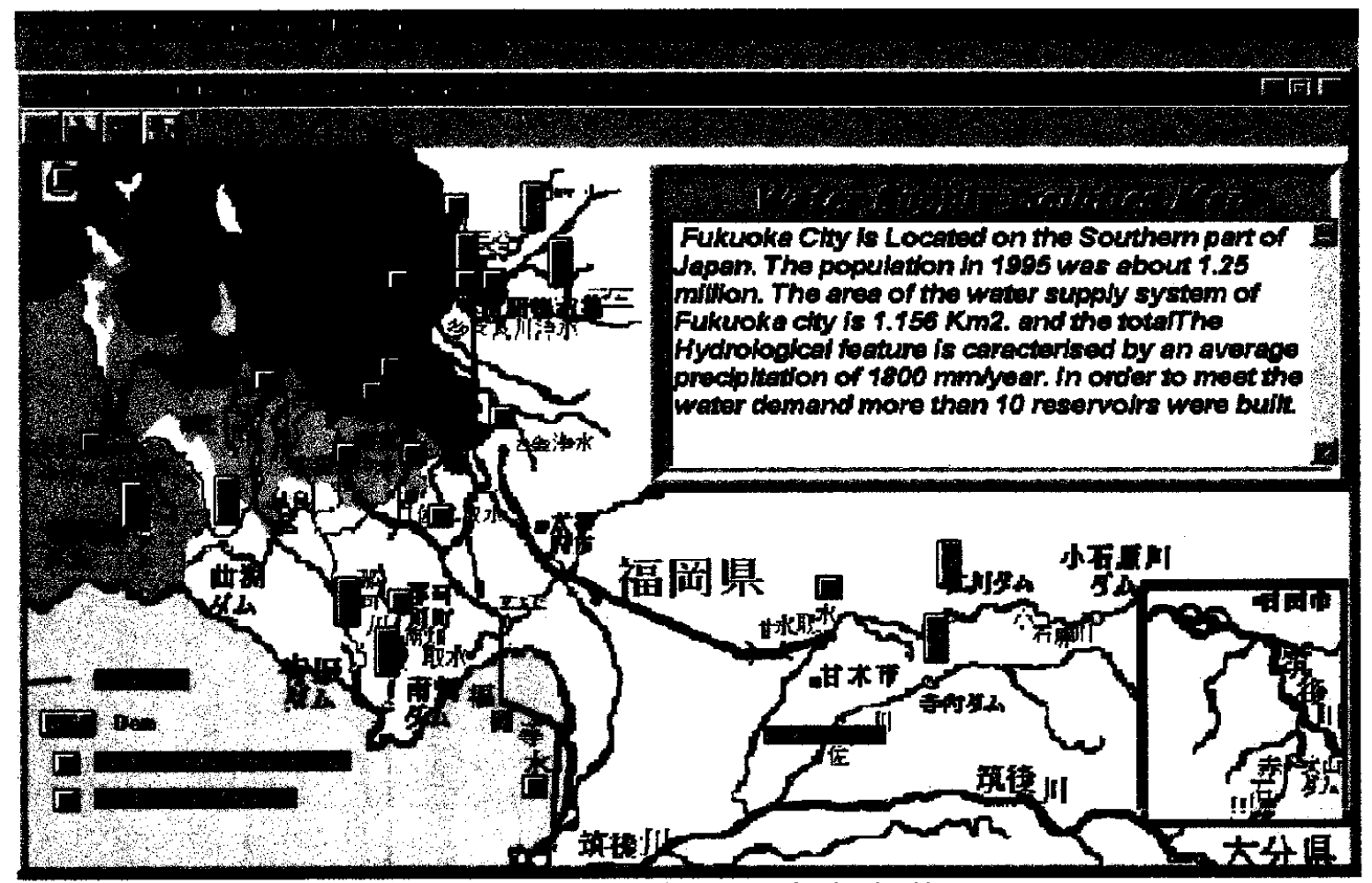

Fig.1. Water supply system of Fukuoka City

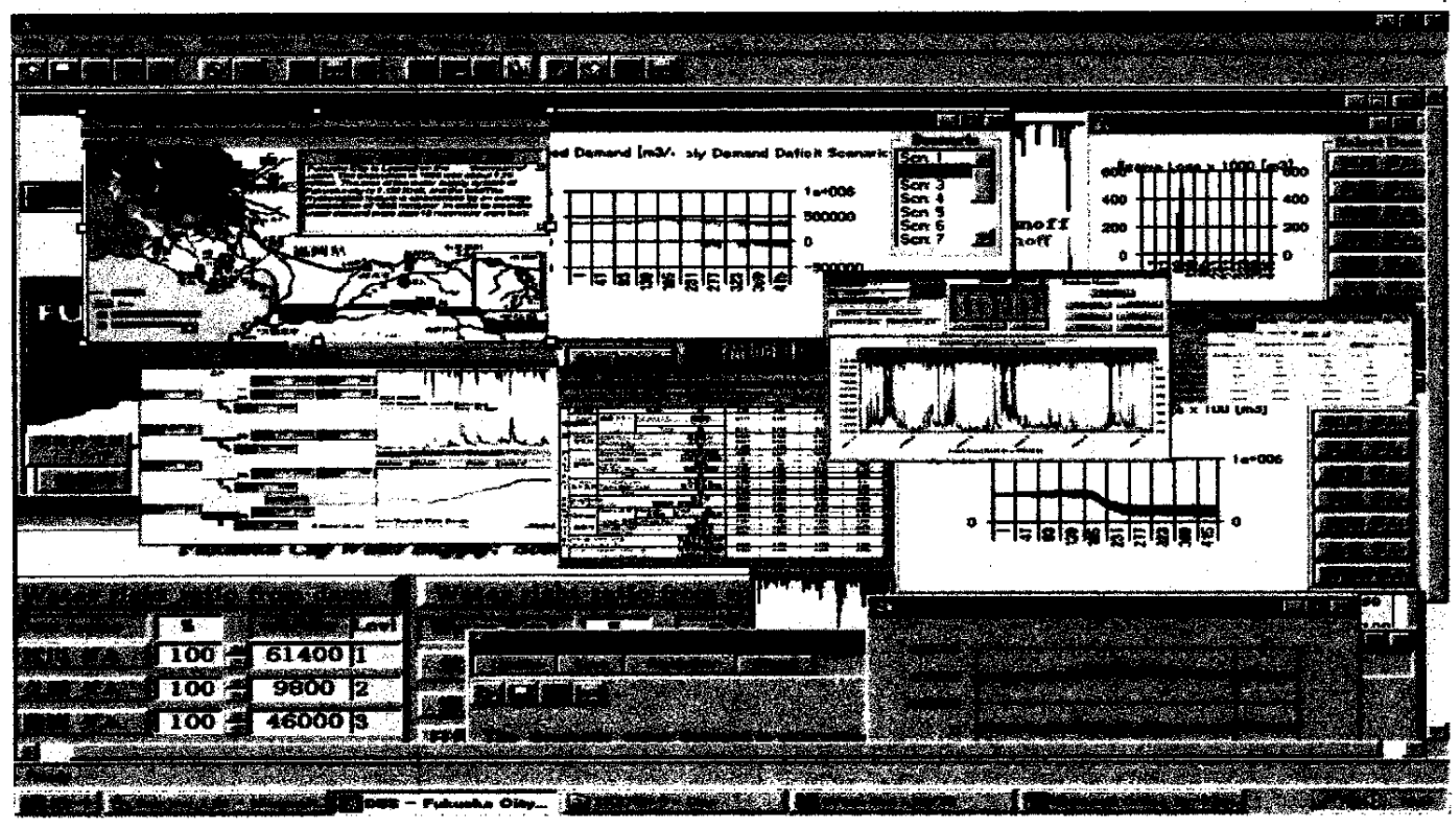

Fig. 2. Enviroment and graphical user interface of the DSS for Fukuoka City water resources management.

refill its capacity. Unusual climatic conditions such as the drought that occurred in 1978 and 1994, the worst on record, cause the system storage to decline to levels that require water use restriction.

\section{DECISION SUPPORT SYSTEM}

The present decision support system is applied to derive the best water take policies, among the existing supply sources that satisfy an acceptable 
risk level that assures a minimum of drought damages.

The DSS integrates two main modules: a database manager and mathematical models. The interaction between the user and all elements of the DSS take place thought a graphical user interface, Fig. 2. The DSS environment is developed under Windows 95/NT and requires $13 \mathrm{MB}$ of free disk space and a minimum of $16 \mathrm{MB}$ of memory ${ }^{5,6)}$.

\section{GENETIC ALGORITHM}

The use of genetic algorithms (GA) as search procedures in optimization and machine learning problems was first proposed by Holland (1975). The $\mathrm{GA}$ is an iterative procedure maintaining a population of structures, i.e., daily water take from each source in our application, termed "chromosomes" or "strings", that are candidate solutions to specific domain changes. During each temporal increment, i.e., "generation", the structures in the current population are rated for their fitness as domain solutions. Based on this evaluation, a new population of candidate solutions is formed using specific genetic operators such as reproduction, crossover, and mutation. Through this reproduction, GAs produce new generations of improved solutions by selecting "parents" with higher fitness ratings or by giving parents greater probability to be contributors.

Recombination of strings in the population of a new generation is affected by crossover. In the present GA procedure, so-called two points crossover is performed on the entire population. This involves a pair of strings exchanging corresponding parts of their gene sequence defined by randomly chosen points. All strings have the chance of undergoing crossover, but not all will participate in the process during a single generation. This is because the probability of crossover occurrence, which must be specified by the user, is usually less than unity.

Besides crossover, after a new population has been generated, mutation is applied to each string in the new population assuming a low mutation rate, i.e., probability. This allows reintroducing genetic diversity to avoid getting trapped in local optima and avoid disruption of proper solutions. Unlike general optimization algorithms, the GA does not rely on any mathematical properties of the objective functions such as differentiability and continuity. This leads to a robust search less likely to get trapped into local optima.

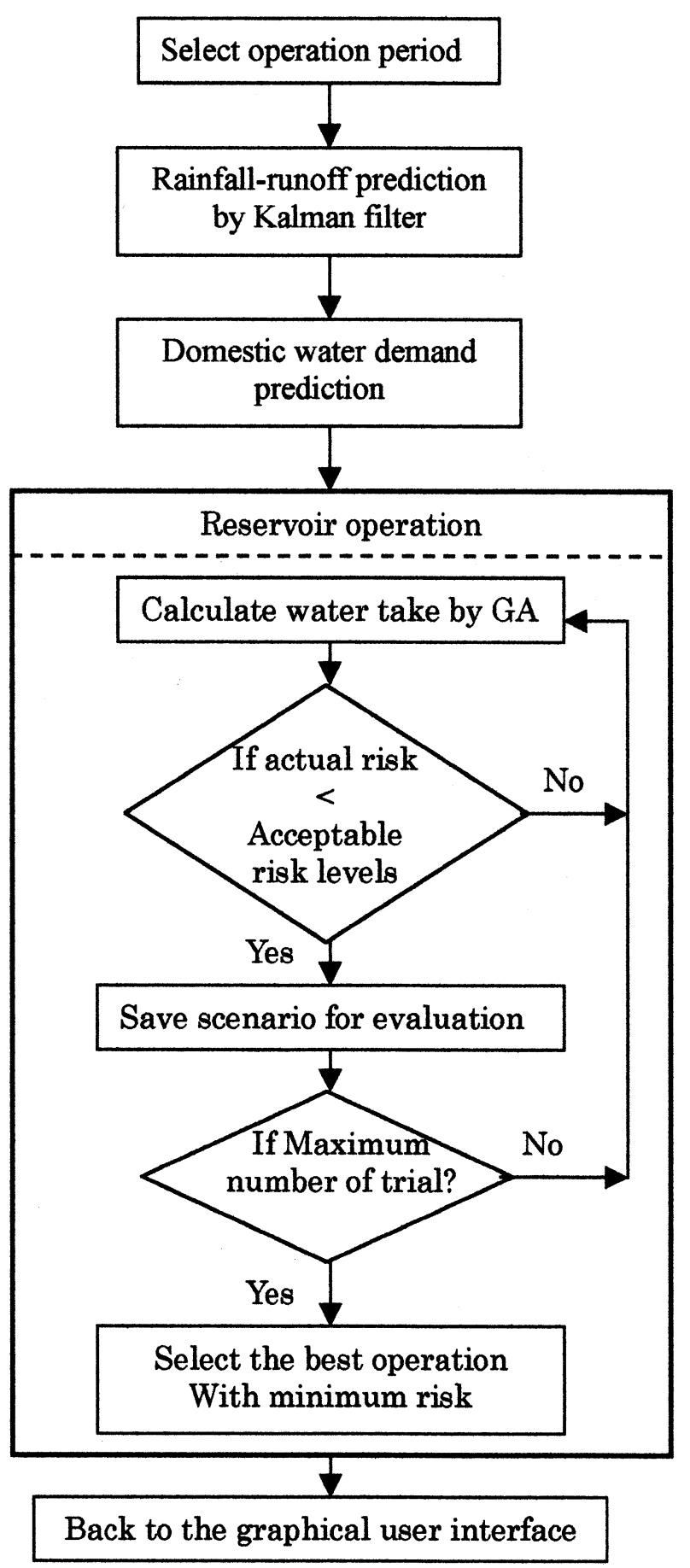

Fig. 3. Reservoir operation flowchart.

\section{RISK ASSESSMENT RESERVOIR OPERATION MODEL}

In the present application, the water supply scenarios derived by the GA procedure are that minimize the drought damages and consequently 
reduce the shortage threats during the operation horizon. Fig. 3 presents the flowchart of the optimization process for the water take alternatives from the existing sources. After selecting the period of interest, the operational procedure is: (1) perform the real-time inflow forecasts to each basin by Kalman filtering integrated in the tank model, (2) estimate the actual water demand, (3) derive optimal water take alternatives by GA, (4) evaluate the risk level for each alternative, (5) modify the operation accordingly.

In the GA scheme, two distinct features are introduced: (1) a combined risk objective function (DRI, eq. 2), and (2) a qualification of selected strings, i.e., water take solutions, as parents for the next generation. In each generation, the drought risk index (DRI) is evaluated for each GA solution, i.e., water take allocation. The strings qualified as parents for the next generation are those being in the risk-based solution space, defined by the risk thresholds. There are two reasons for selecting only the chromosomes, i.e., water take solutions, from the risk-based solution space: (1) speed-up of the convergence process, (2) generation of future chromosomes which cluster within the defined acceptable risk level leading to appropriate practical decisions. The reservoir operation is based on the conservation equation defined by:

$$
S_{t}=S_{t-1}+I_{t}-R_{t}-L_{t} \quad t=1, \ldots, T
$$

where $T$ is the operation period. At each the time step $t, S_{t}$ denotes the water storage, $I_{t}$ the reservoir inflow, $R_{t}$ the total release, and $L_{t}$ the reservoir losses.

In eq. (1) the release decision is subjected to the constraints on storage capacity and maximum water right for domestic water take ${ }^{7}$.

In the reservoir operation model the drought risk index ${ }^{3}$ is uscd as the objective function to evaluate the best water take scenarios that minimize the drought damages. The risk indices reliability $(R e l)$, resiliency $(R e s)$, and vulnerability $(\mathrm{Vul})$ are defined as:

$$
\begin{aligned}
& \text { Rel }=\frac{1}{T} \sum_{i=1}^{T} S S_{t} \\
& \operatorname{Res}=\frac{1}{\frac{1}{N F} \sum_{i=1}^{N F} F S_{i}}
\end{aligned}
$$

$V u l=\sum_{1}^{T} \frac{W d_{t}-W D S_{t}}{W d_{t}}$

where $T$ is the operation period, $S S_{t}$ the satisfactory state of the day $t, N F$ the number of times the system enters a failure state during the period $T, F S_{i}$ the $i$ th failure day, $W d_{t}$ is the daily water demand at day $t$, and $W D S_{t}$ the daily water supply at day $t$.

The drought risk index is then defined as a linear weighting function of reliability, resiliency, and vulnerability:

$D R I=w_{1}(1-\operatorname{Rel})+w_{2}(1-\operatorname{Res})+w_{3} V u l$

where $\sum_{i=1}^{3} w_{i}=1$

In Eq.(5), $w_{1}, w_{2}$, and $w_{3}$ specify the relative weights of the respective risk criteria. As the simplest situations, as used in this study, all weights are assumed to be equal, i.e., $w_{1}=w_{2}=w_{3}=1 / 3$. However, because generally risk is opposite of reliability, it is possible to use $w_{1}=1 / 2$, and $w_{2}=1 / 4$, etc.

As shown in Fig. 4, the four risk indices (1-Rel, l-Res, $V u l$, and $D R I$ ) are used to define the feasible space of the water supply scenarios. In Fig. 4 the total feasible space $(0 \leq 1-\operatorname{Rel} \leq 1,0 \leq 1-\operatorname{Res} \leq 1$, and $0 \leq V u l \leq 1)$ includes all feasible solutions. In term of risk management, the qualified scenarios are all solutions with risk values smaller than or equal to the risk thresholds $(1-R e l)_{\max }$, (1-Res) $)_{\max }$, (Vul $)_{\max }$, and $D R I_{\text {max }}$. On the other hand, solutions with risk indices falling within the shaded space are likely to lead to long-tem drought damages. The drought risk threshold is derived from Eq. (2) with $1-\operatorname{Res} \leq(1-$ $\operatorname{Rel})_{\max }, 1-\operatorname{Res} \leq(1-R e s)_{\max }, V u l \leq V u l_{\max }$. The threshold $(1-R e l)_{\max }$ specifies the maximum acceptable number of failing days, (1-Res) $)_{\max }$ the maximum acceptable length of a failure, and $V u l_{\max }$ the maximum acceptable water restriction. The triangular shape defined by the risk indices value is denoted drought risk aspect.

\section{RESULTS AND DISCUSSIONS}

Table 1 shows the actual 1994/95 drought risk indices, the optimal solution obtained by GA, and a typical GA solution. 


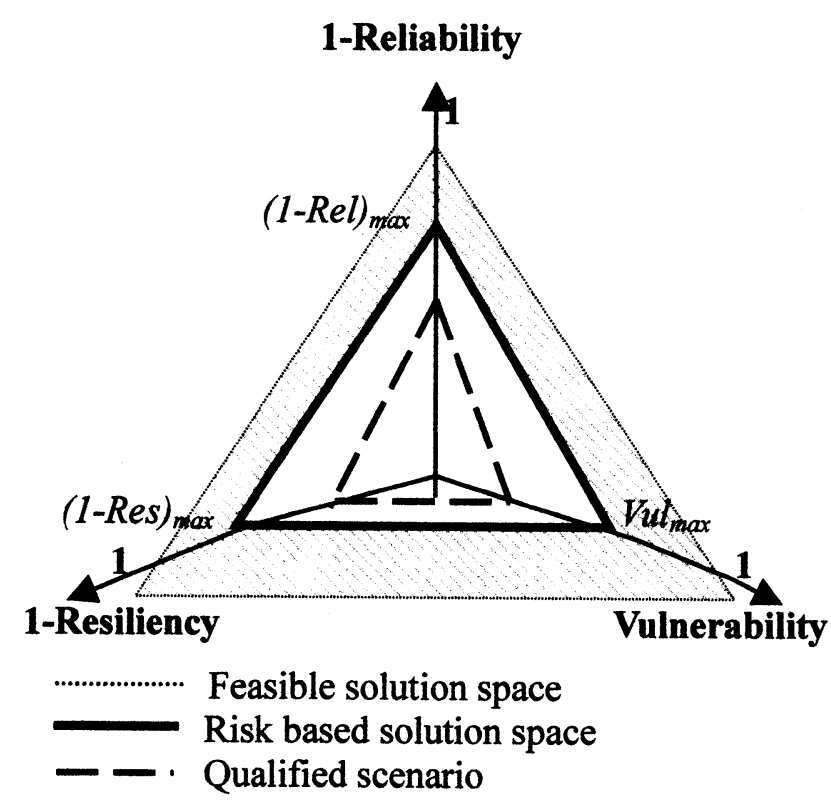

Fig. 4. Non risk management feasible space, acceptable risk, and qualified scenario.
Table 1. Risk indices for two different genetic algorithm runs and comparative results with the $1994 / 95$ risk aspect.

\begin{tabular}{|c|c|c|c|}
\hline Risk & $\begin{array}{c}1994 / 95 \\
\text { drought } \\
\text { operation }\end{array}$ & $\begin{array}{c}\text { Genetic } \\
\text { Algorithm } \\
\text { run 1 }\end{array}$ & $\begin{array}{c}\text { Genetic } \\
\text { Algorithm } \\
\text { run 2 }\end{array}$ \\
\hline $\begin{array}{c}\text { Reliability } \\
(\text { Rel })\end{array}$ & 0.31 & 0.44 & 0.41 \\
\hline $\begin{array}{c}\text { Resiliency } \\
(\text { Res })\end{array}$ & 0.10 & 0.23 & 0.18 \\
\hline $\begin{array}{c}\text { Vulnerability } \\
(V u l)\end{array}$ & 0.11 & 0.15 & 0.16 \\
\hline $\begin{array}{c}\text { Drought risk } \\
\text { index (DRI) }\end{array}$ & 0.56 & 0.49 & 0.52 \\
\hline
\end{tabular}

The actual 1994/95 drought risk aspect and the optimal GA solution are depicted in Fig. 5. Despite a slight gain in the total water storage of Fukuoka City reservoirs, the optimal GA results provides a reduced risk as compared with the actual operation during the 1994/95 drought. As can be seen from Table 1, the drought risk index is decreased from 0.56 to 0.49 despite a small increase in vulnerability from 0.11 for the actual $1994 / 95$ operation to 0.15 for the optimal solution. The second, typical water

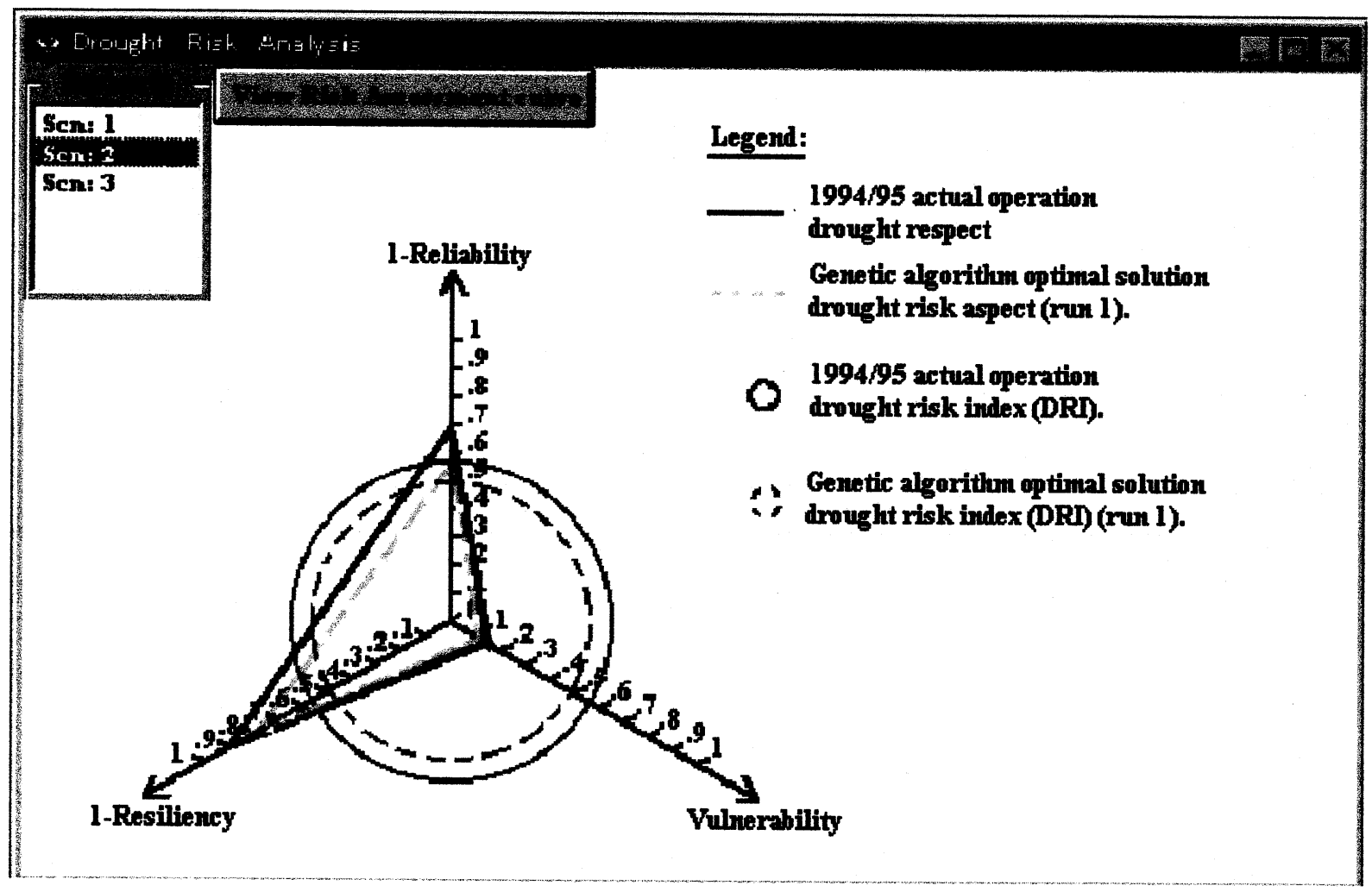

Fig. 5. Drought risk aspect of the $1994 / 95$ drought operation period and genetic algorithm run. 
supply scenario by GA reached a somewhat different solution as can be seen in Table 1 . Although it shows a smaller drought risk index, $\mathrm{DRI}=0.52$, and a higher reliability and resiliency as compared with 1994/995, the vulnerability is not minimized. Therefore, it is concluded that even though the genetic algorithm solution may provide an improved water supply operation of less risk, the calculated risk aspect by GA is likely to fall into local optima.

\section{CONCLUSIONS}

The present DSS was designed to facilitate the examination of sequences of scenarios faster and more accurately than traditional methods allow. It provides a number of mathematical modeling frameworks involving tools for database management, simulation and optimization. This study shows some of the potential of the risk based optimal operation that the DSS may offer to water resources analysts. The application of genetic algorithm theory to derive the water supply decision based on the concept of acceptable risk is very promising.

ACKNOWLEDGMENTS This study has been partially supported by CTI Engineering Co. Ltd., Fukuoka branch, Japan. The authors wish to acknowledge Jonas Olsson, Kyushu University, for his assistance and valuable suggestions. The authors wish also to acknowledge two anonymous reviewers for their insightful comments.

\section{REFERENCES}

1) Holland, J.H.: Adaptation in natural and artificial systems. Ann. Arbor: The university of Michigan press, 1975.

2) Hashimoto, T., Stedinger, J.R., \& Loucks, D.P.: Reliability, resiliency, vulnerability criteria for water resources system performance evaluation, Water Resouces Research, Vol. 18(1), pp. 2917 2924, 1982.

3) Jinno, K., Xu, Z., Kawamura, A., \& Tajiri, K.: Risk assessment of water supply system during drought. International Journal of Water Resources Development, 11(2), pp. 185-204, 1995.

4) Waterworks Bureau: On the 1994 drought records, Report No 12, Fukuoka City (in
Japanese), 1996.

5) Merabtene, T., Jinno, K., \& Kawamura, A.: Decision support system for the water resources management, Japan Society of Civil Engineers Proc. of the 5th Symposium on Water Resources, 461-466. 1997a.

6) Merabtene, T., Jinno K., Kawamura A., \& Matsunaga T.: Interactive user interface for rainfall-runoff analysis by tank model, Memoirs of the Faculty of Engineering, Kyushu University, 57(3), pp. 107-120, $1997 \mathrm{~b}$.

7) Merabtene, T., Jinno, K., and Kawamura, A.: Integrated decision support system for drought risk management of water supply system, $11^{\text {th }}$ congress of the IAHR-APD, pp.109-118, 1998.

(Received September 30, 1998) 